BRAVILLIAN JOURNAL

www.bjournal.com.br
ISSN 0100-879X

Volume 43 (5) 381-496 May 2011

BIOMEDICAL SCIENCES

AND

CLINICAL INVESTIGATION

Braz J Med Biol Res, May 2011, Volume 44(5) 381-387

doi: 10.1590/S0100-879X2011007500035

Leptin and adiponectin in the female life course

S.B. Lecke, D.M. Morsch and P.M. Spritzer

The Brazilian Journal of Medical and Biological Research is partially financed by

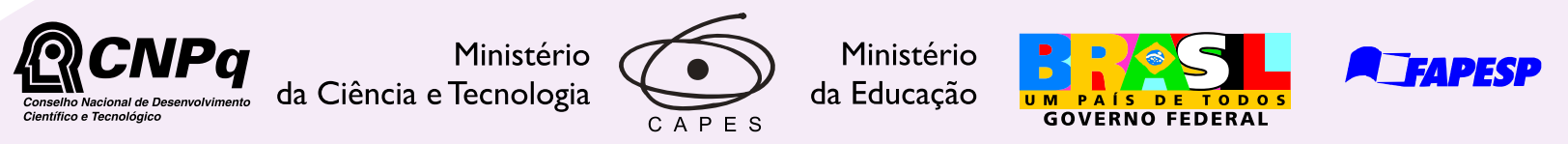

Institutional Sponsors

scie/
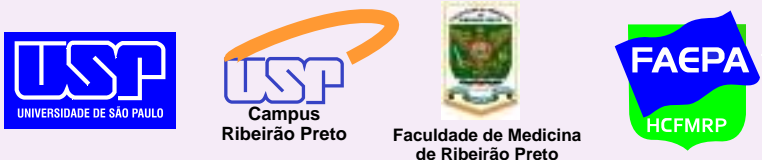

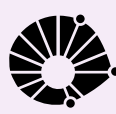

UNICAMP
Ф SHIMADZU

GE Healthcare
Hotsite of proteomics metabolomics developped by:

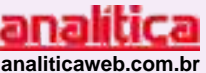

Thermo SCIEN T IFIC 


\title{
Leptin and adiponectin in the female life course
}

\author{
S.B. Lecke, D.M. Morsch and P.M. Spritzer
}

Unidade de Endocrinologia Ginecológica, Serviço de Endocrinologia, Hospital de Clínicas de Porto Alegre, Laboratório de Endocrinologia Molecular, Departamento de Fisiologia, Universidade Federal do Rio Grande do Sul, and Instituto Nacional de Hormônios e Saúde da Mulher - CNPq, Porto Alegre, RS, Brasil

\begin{abstract}
Adipose tissue secretes a variety of adipokines, including leptin and adiponectin, which are involved in endocrine processes regulating glucose and fatty metabolism, energy expenditure, inflammatory response, immunity, cardiovascular function, and reproduction. The present article describes the fluctuations in circulating leptin and adiponectin as well as their patterns of secretion in women from birth to menopause. During pregnancy, leptin and adiponectin seem to act in an autocrine/paracrine fashion in the placenta and adipose tissue, playing a role in the maternal-fetal interface and contributing to glucose metabolism and fetal development. In newborns, adiponectin levels are two to three times higher than in adults. Full-term newborns have significantly higher leptin and adiponectin levels than preterms, whereas small-for-gestational-age infants have lower levels of these adipokines than adequate-for-gestational-age newborns. However, with weight gain, leptin concentrations increase significantly. Children between 5 and 8 years of age experience an increase in leptin and a decrease in adiponectin regardless of body mass index, with a reversal of the newborn pattern for adiponectin: plasma adiponectin levels at age five are inversely correlated with percentage of body fat. In puberty, leptin plays a role in the regulation of menstrual cycles. In adults, it has been suggested that obese individuals exhibit both leptin resistance and decreased serum adiponectin levels. In conclusion, a progressive increase in adiposity throughout life seems to influence the relationship between leptin and adiponectin in women.
\end{abstract}

Key words: Female; Adiposity; Leptin; Adiponectin

\section{Introduction}

Adipose tissue is currently recognized as a dynamic organ because of its capacity to secrete hormones and cytokines. White adipose tissue, the predominant form found in adults (brown fat is mainly found in neonates), consists of preadipocytes and adipocytes, macrophages, endothelial cells, fibroblasts, and leukocytes (1), and secretes a variety of adipokines. These adipokines are involved in a range of endocrine processes that regulate glucose and fatty metabolism, energy expenditure, inflammatory response, immunity, cardiovascular function, and reproduction, among other functions $(2,3)$.

Several aspects related to leptin and adiponectin have been extensively studied, including their metabolic, clinical, and pharmacological characteristics. However, the behavior of these adipokines over the course of life has received less attention. In the present article, fluctuations in circulating leptin and adiponectin as well as their patterns of secretion from birth to menopause are reviewed in order to trace a physiological profile of these adipokines in the female life course.

\section{Leptin and adiponectin}

Since its discovery in 1994, leptin has opened a wide field for research on the biology of adipocytes, including their metabolic and endocrine roles as well as the relationships between adipose secretagogues and peripheral tissues. Leptin, the product of the $O B$ gene located at 7q31.3, provides a molecular basis for the lipostatic theory of the regulation of energy balance (4). It has become clear that leptin also plays an important role in reproduction, both during pregnancy and early neonatal life (4). Leptin is produced by adipocytes and also by the placenta (5). It has been shown to act as an afferent satiety signal regulating appetite and weight in humans and rodents (6) by suppressing food intake and increasing energy consumption (2). Leptin circulates as a monomeric $16-\mathrm{kDa}$ protein or bound to leptin-binding

Correspondence: P.M. Spritzer, Serviço de Endocrinologia, Hospital de Clínicas de Porto Alegre, Rua Ramiro Barcelos, 2350, 90035-003 Porto Alegre, RS, Brasil. Fax: +55-51-3359-8027/8777. E-mail: spritzer@ufrgs.br

Received December 9, 2010. Accepted March 4, 2011. Available online March 25, 2011. Published May $16,2011$. 
proteins, forming large, high-molecular weight complexes (7), and acts by interacting with the leptin receptor (Ob-R). The Ob-R family is a large single-transmembrane-domain protein belonging to the class I cytokine receptor family $(8,9)$. The Ob-R gene encodes at least five alternatively spliced variants. The long form of $\mathrm{Ob}-\mathrm{R}$ is considered to be the active leptin receptor, while the shorter forms lack the membrane-spanning region and are believed to be involved in leptin transport (10) (Figure 1). Ob-R is found in regions of the hypothalamus, the gonadotropic cells of the anterior pituitary gland, the ovarian interstitial cells, the theca and granulosa cells of ovarian follicles, the endometrium, and the Leydig cells of the seminiferous tubules (11). Moreover, $\mathrm{Ob}-\mathrm{R}$ has been identified in the kidneys, heart, lungs, liver,

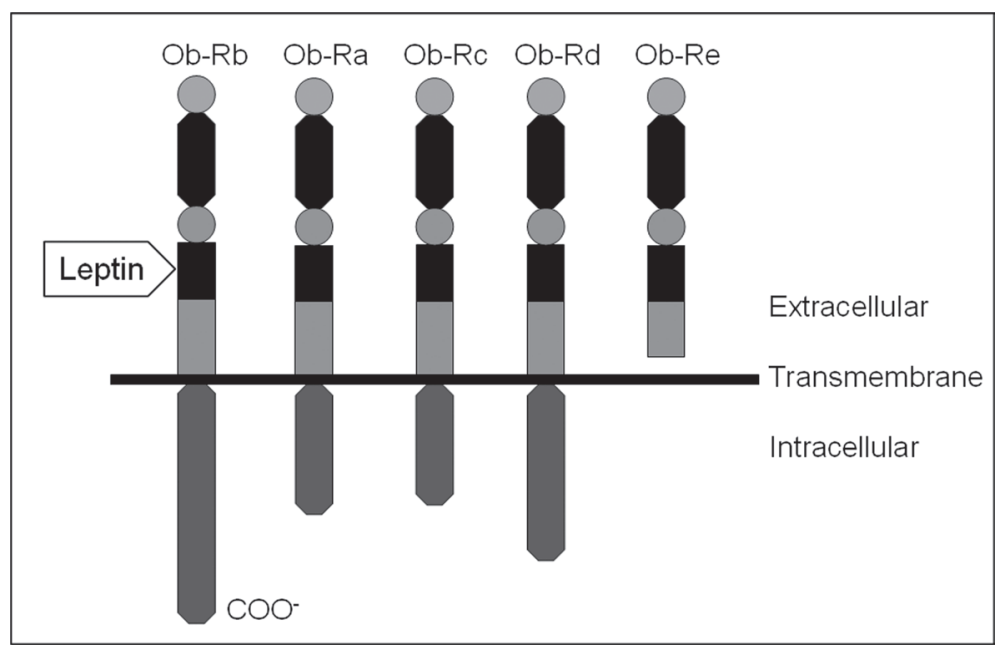

Figure 1. Representation of leptin receptor forms (Ob-R; subunits a to e). All share identical extracellular ligand-binding domains, but differ at the C-terminus. The long form of the Ob-R (Ob-Rb) is considered to be the active leptin receptor, activating the intracellular signal transduction pathway.

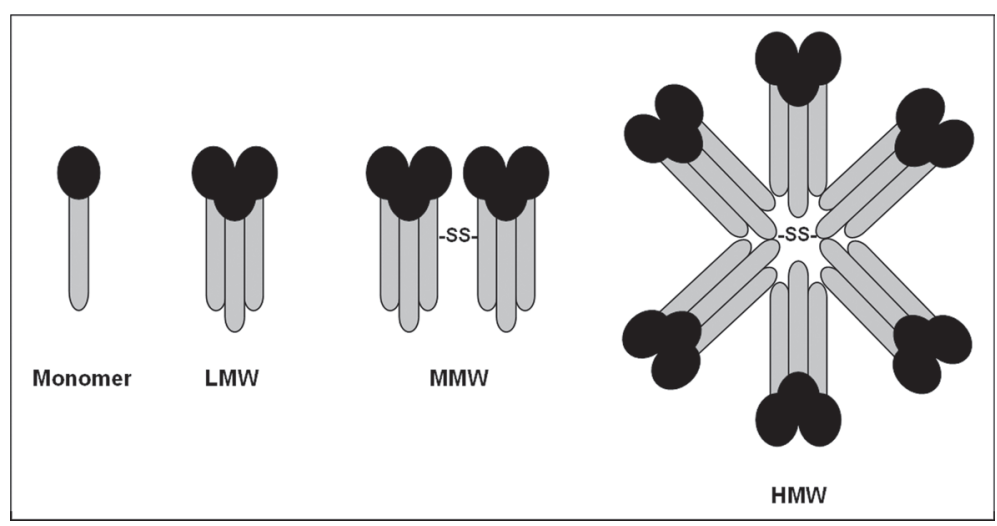

Figure 2. Representation of the circulating adiponectin forms. LMW = low molecular weight; $\mathrm{MMW}$ = middle molecular weight; $\mathrm{HMW}$ = high molecular weight; $\mathrm{SS}=$ disulfide bond . and skeletal muscle (12).

Adiponectin was first discovered in 1995 as a protein released exclusively by adipose tissue (13). Because it was found simultaneously by several laboratories, adiponectin received various names - adipocyte complement-related protein of $30 \mathrm{kDa}$ (Acrp30), adipose-specific gene adipoQ (AdipoQ), adipose most abundant gene transcript 1 (apM1), and gelatin-binding protein of $28 \mathrm{kDa}$ (GBP28) (14). Adiponectin is the protein product of the APM1 gene transcript, which is located on chromosome $3 q 27$, close to the locus for type II diabetes and adiposity (15). This adipokine is secreted by adipose tissue as a low molecular weight trimer, as a combination of two middle molecular weight trimers, or as six high molecular weight (HMW) trimers, and circulates either as a trimer or as an oligomer (Figure 2). HMW forms are the predominant and active forms in human serum (16). Adiponectin increases fatty acid oxidation in adipose tissue, liver and muscle, enhancing insulin sensitivity, and inhibits inflammatory mediators and the expression of adhesion molecules within the vascular wall, lowering atherogenic risk $(1,16)$. Adiponectin receptors have been identified predominantly in muscle (AdipoR1) and liver cells (AdipoR2), although in humans they are expressed ubiquitously in the body and brain $(2,14,17)$.

In most studies, circulating levels of leptin and adiponectin have been determined by enzyme-linked immunosorbent assays or enzyme immunoassay, or, alternatively, by radioimmunoassay (associated or not with in-house techniques). While many studies have described assay sensitivity and intra- and interassay coefficients of variation, quality control measurements have been rarely reported.

\section{Pregnancy and intrauterine and neonatal development}

During pregnancy, development of the neonate is influenced by critical interactions among genes, epigenetic changes, hormones, nutrition, the intrauterine environment, and early pre- and postnatal events.

It has been reported that the increased leptin levels found in pregnant women result from placental secretion, in addition to adipose tissue production $(5,18)$. The higher leptin levels that occur during pregnancy have also been attributed to weight gain and to an increase in body mass index (BMI), as well as to changes in levels of hormones that might stimulate leptin secretion (e.g., 
insulin, estrogens and human chorionic gonadotropin) (19). Trophoblastic cells, the predominant placental cell type, are the most likely source of placental leptin $(5,20)$. Caminos et al. (21) were the first to demonstrate the presence of adiponectin and AdipoR2 in human and rat cytotrophoblast and syncytiotrophoblast placental cells. Chen et al. (1) described the production of adiponectin and the presence of both adiponectin receptors in the human placenta, indicating that the placenta also secreted adiponectin in vitro. It appears that leptin and adiponectin act in an autocrine/paracrine fashion in the placenta, playing an important role in the maternal-fetal interface and contributing to glucose metabolism and fetal development during pregnancy $(1,17,19)$.

If prematurity or fetal growth restrictions prevent the fetus from acquiring sufficient adipose tissue, changes are observed in the cord blood adipokine profile. Martos-Moreno et al. (22) reported that full-term newborns had significantly higher leptin and adiponectin levels than preterms, while babies who were small for gestational age had lower levels of these adipokines than adequate-for-gestational-age newborns. In that study, gestational age was the main predictor of adiponectin levels, while birth weight correlated independently with leptin cord blood levels. Nevertheless, increases in fetal weight also enhanced cord blood adiponectin levels, indicating that the negative influence of fat mass on adiponectin secretion is absent in the fetus (22).

Mantzoros et al. (23) have confirmed that adiponectin levels are two to three times higher in neonates than in adults. One possible explanation is that neonates have significantly less fat mass than children and adults, and that their fat mass consists mainly of subcutaneous fat and brown adipose tissue, which is atrophic in adults. In this regard, other investigators have reported a positive association between cord blood total adiponectin as well as HMW adiponectin levels (24) and birth weight, BMI, birth weight-to-length ratio, and leptin levels $(25,26)$, even though this was not confirmed by others (27). Some studies have also provided evidence that high concentrations of leptin can be found in the cord serum of full-term newborns, being closely related to birth weight and fat accumulation $(28,29)$. These findings imply that the relationship between leptin and body fat mass may develop early in life.

Previous studies of preterm infants have shown that serum leptin concentrations were significantly lower than those found in appropriate-for-gestational-age neonates (30). However, as weight gain progressed, leptin concentrations increased significantly $(5,19,31)$. It has been speculated that these increased leptin levels may derive from the increase in adipose fat typically observed after the under-nutrition period in preterm infants, suggesting a possible involvement of leptin in the early development of insulin resistance $(32,33)$. A series of epidemiological human and experimental animal studies have shown that exposure to inadequate (high or low) nutrition during fetal and postnatal life, as well as reduced fetal growth followed by excessive postnatal catch-up in height and particularly, in weight, increase the risk of obesity, insulin resistance and type 2 diabetes in childhood and adult life (34). The decrease in adiponectin that occurs in small-for-gestational-age infants with the greatest weight catch-up has also been reported as a risk factor for subsequent development of visceral fat and insulin resistance $(17,26)$.

Disturbances in fetal nutrient supply affect adipocyte levels. Muhlhausler and Smith (34) have proposed that prenatal over-nutrition promotes growth of the subcutaneous fat depot, leading to increased leptin secretion and serum levels. In fact, hyperleptinemia during neonatal life may program leptin resistance via dual effects on food intake and energy expenditure, with long-term adverse consequences for the hypothalamic circuits regulating energy balance $(2,35)$. Some studies have shown an increased risk for obesity and insulin resistance in neonates born to obese mothers, as well as higher levels of leptin and markers of inflammation than in infants born to lean mothers (36).

A study of 100 mother/newborn pairs has tried to determine the production of leptin in the uterus and its role in neonatal development. Although maternal serum leptin concentrations correlated with measures of pre- and post-gestational adiposity, there was no association between serum leptin levels in the newborn, an observation confirmed by others $(5,9)$. Interestingly, Hassink et al. (5) demonstrated that $13 \%$ of newborns had higher serum leptin concentrations than their mothers, suggesting that the fetus may produce its own leptin, with associated leptin resistance, and/or that the placenta is the major source of leptin production for the fetus. However, Ho et al. (30) have shown a correlation between neonatal serum leptin concentrations and maternal weight and BMI within 24 hours of birth, suggesting that maternal and even placental production of leptin may be involved in the early regulation of fetal metabolism and growth. As in previous studies, no association was demonstrated between neonatal adiponectin levels and maternal age or pre-pregnancy BMI, suggesting that neonatal adiponectin levels are largely independent of maternal influence (25). Bozzola et al. (32) evaluated both total and isoform adiponectin circulating levels in a cohort of infants, and found a significant increase from birth up to the first month of life, followed by a decline at one year of age in all subjects. The investigators argued that the observed fall in serum adiponectin levels may be a consequence of increased adiposity, confirming the negative association between serum adiponectin levels and percentage of body fat, as is the case in older children (32).

\section{Childhood and puberty}

Obesity and its associated metabolic and psychological comorbidities have become a major health problem in children. 
Between 5 and 8 years of age, metabolic health appears to improve regardless of BMI, with an increase in leptin and a decrease in adiponectin (37). In fact, adiponectin levels in childhood show a marked reversal of the positive body mass correlations observed during the neonatal period: plasma adiponectin levels at age 5 are inversely correlated with percentage of body fat. This inverse association between $\mathrm{BMI}$ and adiponectin becomes even more marked in older children $(26,38)$. Previous studies in children of different ethnicities have reported that low plasma adiponectin concentrations were closely related to hyperinsulinemia $(38,39)$, leading to a long-term increased risk for diabetes.

There is a developmental increase in adipose tissue leptin expression and secretion during childhood, reaching maximal capacity in puberty/adulthood. Leptin may be regarded as a link between food intake, energy expenditure and the reproductive system. A possible interpretation is that leptin may signal to the body that energy reserves are adequate for reproduction, representing one of the primary mechanisms linked to the onset of puberty $(11,12,40)$. In fact, a minimal leptin concentration is necessary to activate the hypothalamus-pituitary-gonadal axis, triggering puberty and maintaining reproductive function.

The temporal correlation between increases in leptin concentration and the initiation of luteinizing hormone (LH) pulsatility over peripuberty has been studied in several species. It is well recognized that leptin stimulates the gonadotropin-releasing hormone $(\mathrm{GnRH})$ pulse generator and in turn LH pulses. This adipokine is secreted in a pulsatile manner in ovulatory women: a peak at night followed by a gradual change in LH pulsatility, reaching a nadir in the morning $(7,41)$. In turn, in polycystic ovary syndrome (PCOS), a condition associated with androgen excess and chronic anovulation, circulating leptin seems to be related to the overall and central adiposity that is frequently associated with this syndrome (42). In fact, data from our group suggest that the attenuation of the response of $\mathrm{LH}$ to $\mathrm{GnRH}$ in obese PCOS women may be related to changes in $\mathrm{GnRH}$ oscillator activity caused by a leptin-resistant state (42).

Interestingly, the nightly leptin peak has been associated with acute changes in LH pulses in normal ovulatory women, followed by a decline in metabolic rate (41). These data suggest that a single metabolic cycle regulates the leptin peak and the slowing of $\mathrm{LH}$ and metabolic rate. Conversely, both leptin resistance/hyperleptinemia, as observed in obesity and PCOS (42), and decreased circulating leptin, as observed in women with nutritional disorders or athletes, are associated with impaired gonadal steroidogenesis and reproduction (12). The role of leptin in the regulation of the menstrual cycles is further supported by studies demonstrating that menstrual irregularities and amenorrhea are common in women with very high or very low leptin levels $(11,19)$. Evidence suggests that leptin functions as a permissive, rather than a direct triggering factor at the onset of puberty, working in concert with other metabolic signals, such as insulin and insulin-like growth factor, amino acids, and neuropeptides $(2,12,19)$.

\section{Adulthood and postmenopause}

In adults, circulating levels of leptin increase in the presence of total and central obesity and in metabolic disturbances $(12,42,43)$, while adiponectin levels are inversely associated with the degree of adiposity. It has been suggested that obese individuals exhibit both leptin resistance, which antagonizes the metabolic action of insulin, and decreased serum adiponectin levels, increasing the risk for type 2 diabetes, coronary artery disease and metabolic syndrome (44).

Leptin concentrations may vary during the physiological

Table 1. Serum leptin and adiponectin concentrations during the female life course.

\begin{tabular}{lccc}
\hline Phase of life & Leptin & Adiponectin & References \\
\hline Neonate & & & $22,24-30$ \\
$\quad$ Small-for-gestational-age and/or undernourished & $\downarrow$ & $\downarrow$ & \\
$\quad$ Adequate-for-gestational-age & $\leftrightarrow$ & $\leftrightarrow$ & \\
$\quad$ Large-for-gestational-age and/or overnourished & $\uparrow \uparrow$ & $\uparrow \uparrow$ & \\
Childhood & $\leftrightarrow$ & $\leftrightarrow$ & $26,32,37,38$ \\
Puberty & $\uparrow$ & $\leftrightarrow$ & $11,12,40$ \\
Adulthood & & & $12,42-44$ \\
$\quad$ Lean women & $\leftrightarrow$ & $\leftrightarrow$ & \\
$\quad$ Overweight/obese women & $\uparrow$ & $\downarrow$ & \\
Post-menopause & & & $55-57,60$ \\
$\quad$ Lean women & $\leftrightarrow$ & $\uparrow \downarrow$ & \\
$\quad$ Overweight/obese women & $\uparrow$ & $\downarrow$ & \\
\hline
\end{tabular}

$\uparrow=$ increased; $\downarrow$ = decreased; $\leftrightarrow$ = no alteration; $\uparrow \downarrow=$ not established. 
menstrual cycle, exhibiting a monthly rhythm in ovulatory women. These variations are related to hormone changes, especially those of serum estradiol concentration along the cycle, despite the absence of variation in total body fat and weight (45). Previous studies on middle-aged, normoweight ovulatory women demonstrated that serum leptin levels were significantly lower during the follicular phase of the menstrual cycle as compared to the midcycle and luteal phases (46). Hardie et al. (47) have also demonstrated higher serum leptin concentrations during the luteal phase. However, as observed by our group, adult women show great variability in leptin levels that may mask the subtle differences observed in phases of the menstrual cycles [12.7 (6.2-16.9) vs $8.6(3.5-22.9) \mathrm{ng} / \mathrm{mL}$ in the follicular vs luteal phase, respectively, $\mathrm{P}=0.436]$ (48). As is the case for circulating leptin, food intake also exhibits a similar monthly rhythm in ovulatory women, as documented in the premenstrual dysphoric syndrome: a nadir around the time of ovulation when estrogen is elevated, and an increase following ovulation and during the luteal phase, when progesterone is dominant $(49,50)$.

Asimakopoulos et al. (46) have not found an association between serum adiponectin levels, sex steroids, and other adipokines in middle-aged, normoweight ovulatory women, demonstrating that mean adiponectin concentrations remained practically stable during the menstrual cycle. In addition, no significant changes in serum adiponectin concentrations were reported by Kleiblova et al. (51) in relation to sex hormones or to the degree of insulin sensitivity during the menstrual cycle. In this regard, Rouen et al. (52) observed no variation in adiponectin secretion during the menstrual cycle. These findings suggest that adiponectin is probably not related to reproductive functions in adult women. However, Galvan et al. (53) reported that serum adiponectin concentrations were lower in the postovulatory phase in healthy ovulatory women.

The way leptin and adiponectin regulate metabolic homeostasis is different in some aspects and complementary in others (54). Numerous factors, including body weight and fat composition, insulin resistance and associated metabolic disturbances, diet, and physical activity, are believed to play a role in serum leptin and adiponectin concentrations $(11,12,44)$.

Evidence suggests that the risk for insulin resistance increases after menopause, and that it may be related to the decline in estrogen (53) and may be predominantly influenced by $\mathrm{BMI}(55,56)$. In fact, postmenopausal accumulation of abdominal fat and obesity promote abnormal adipokine secretion, particularly increasing serum leptin levels, and contribute to insulin resistance (57). Adipose tissue accumulation in the abdominal cavity has been proposed as a mediator of obesity-related metabolic disorders (58), leading to the development of components of the metabolic syndrome and further enhancing postmenopausal cardiovascular risk in women.

There are contradictory reports regarding serum adiponectin levels after menopause: some reported a decrease (55), while others found no change (57) or even detected increased serum adiponectin concentrations (59). In a cross-sectional study with amenorrheic Mexican women presenting climacteric symptoms and not on hormone replacement therapy, serum adiponectin levels showed no significant variation when compared with those of women with normal menstrual cycles (60). In addition, serum adiponectin levels were significantly decreased, whereas serum leptin levels were increased in obese postmenopausal women compared to normoweight women (57). Adiponectin concentration appears to be higher in normoweight than in overweight women in early postmenopause (52). Taken together, these data support the idea of an inhibitory role for both estrogen and body fat composition in the secretion of this adipokine.

In conclusion, a progressive increase in adiposity throughout life seems to influence the relationship between leptin and adiponectin in women: serum adiponectin levels decrease, while circulating leptin levels markedly increase with body fat mass (Table 1, Figure 3). Moreover, leptin levels appear to be synchronous with hormone fluctuations and metabolic needs throughout the menstrual cycle, promoting

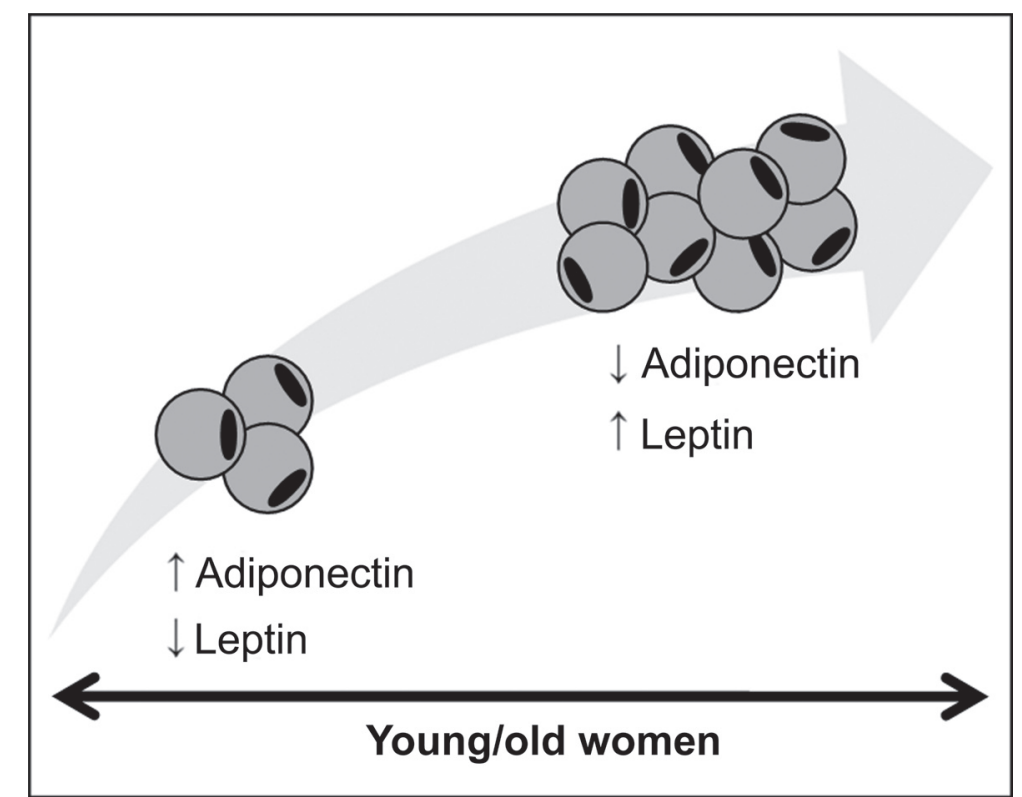

Figure 3. Serum levels of leptin and adiponectin in different phases of the female life course. Serum adiponectin concentrations decrease, while serum leptin levels markedly increase with adiposity. 
an interaction between the reproductive system, food intake and energy expenditure. Further studies are warranted to elucidate the relevance of leptin and adiponectin to fetal/ neonatal development, as well as possible interactions of these adipokines with fetal/neonatal growth and energy homeostasis. Also, while the role of leptin in puberty onset is well established, possible interactions between adiponectin and reproduction have yet to be elucidated.

\section{References}

1. Chen J, Tan B, Karteris E, Zervou S, Digby J, Hillhouse EW, et al. Secretion of adiponectin by human placenta: differential modulation of adiponectin and its receptors by cytokines. Diabetologia 2006; 49: 1292-1302.

2. Henry BA, Clarke IJ. Adipose tissue hormones and the regulation of food intake. J Neuroendocrinol 2008; 20: 842-849.

3. Hausman GJ, Barb CR. Adipose tissue and the reproductive axis: biological aspects. Endocr Dev 2010; 19: 31-44.

4. Kiess W, Reich A, Meyer K, Glasow A, Deutscher J, Klammt $\mathrm{J}$, et al. A role for leptin in sexual maturation and puberty? Horm Res 1999; 51 (Suppl 3): 55-63.

5. Hassink SG, de Lancey E, Sheslow DV, Smith-Kirwin SM, O'Connor DM, Considine RV, et al. Placental leptin: an important new growth factor in intrauterine and neonatal development? Pediatrics 1997; 100: E1.

6. Zhang Y, Proenca R, Maffei M, Barone M, Leopold L, Friedman JM. Positional cloning of the mouse obese gene and its human homologue. Nature 1994; 372: 425-432.

7. Grumbach MM. The neuroendocrinology of human puberty revisited. Horm Res 2002; 57 (Suppl 2): 2-14.

8. Tartaglia LA, Dembski M, Weng X, Deng N, Culpepper J, Devos $\mathrm{R}$, et al. Identification and expression cloning of a leptin receptor, OB-R. Cell 1995; 83: 1263-1271.

9. Schubring C, Englaro P, Siebler T, Blum WF, Demirakca T, Kratzsch J, et al. Longitudinal analysis of maternal serum leptin levels during pregnancy, at birth and up to six weeks after birth: relation to body mass index, skinfolds, sex steroids and umbilical cord blood leptin levels. Horm Res 1998; 50: 276-283.

10. Butte NF, Hopkinson JM, Nicolson MA. Leptin in human reproduction: serum leptin levels in pregnant and lactating women. J Clin Endocrinol Metab 1997; 82: 585-589.

11. Moschos S, Chan JL, Mantzoros CS. Leptin and reproduction: a review. Fertil Steril 2002; 77: 433-444.

12. Goumenou AG, Matalliotakis IM, Koumantakis GE, Panidis DK. The role of leptin in fertility. Eur J Obstet Gynecol Reprod Biol 2003; 106: 118-124.

13. Scherer PE, Williams S, Fogliano M, Baldini G, Lodish HF. A novel serum protein similar to $\mathrm{C} 1 \mathrm{q}$, produced exclusively in adipocytes. J Biol Chem 1995; 270: 26746-26749.

14. Kadowaki T, Yamauchi T. Adiponectin and adiponectin receptors. Endocr Rev 2005; 26: 439-451.

15. Kissebah AH, Sonnenberg GE, Myklebust J, Goldstein M, Broman K, James RG, et al. Quantitative trait loci on chromosomes 3 and 17 influence phenotypes of the metabolic syndrome. Proc Natl Acad Sci U S A 2000; 97: 14478-14483.

16. Michalakis KG, Segars JH. The role of adiponectin in reproduction: from polycystic ovary syndrome to assisted

\section{Acknowledgments}

Research supported by CNPq (INCT \#573747/2008$3)$, CAPES (\#1289/05) and Fundo de Apoio à Pesquisa do Hospital de Clínicas de Porto Alegre (FIPE-HCPA \#340/2004), Brazil.

reproduction. Fertil Steril 2010; 94: 1949-1957.

17. Savino F, Petrucci E, Nanni G. Adiponectin: an intriguing hormone for paediatricians. Acta Paediatr 2008; 97: 701705.

18. Mise H, Yura S, Itoh H, Nuamah MA, Takemura M, Sagawa $\mathrm{N}$, et al. The relationship between maternal plasma leptin levels and fetal growth restriction. Endocr J 2007; 54: 945951.

19. Caprio M, Fabbrini E, Isidori AM, Aversa A, Fabbri A. Leptin in reproduction. Trends Endocrinol Metab 2001; 12: 65-72.

20. Sagawa N, Yura S, Itoh H, Kakui K, Takemura M, Nuamah MA, et al. Possible role of placental leptin in pregnancy: a review. Endocrine 2002; 19: 65-71.

21. Caminos JE, Nogueiras R, Gallego R, Bravo S, Tovar S, Garcia-Caballero $\mathrm{T}$, et al. Expression and regulation of adiponectin and receptor in human and rat placenta. $J$ Clin Endocrinol Metab 2005; 90: 4276-4286.

22. Martos-Moreno GA, Barrios V, Saenz de Pipaon M, Pozo J, Dorronsoro I, Martinez-Biarge M, et al. Influence of prematurity and growth restriction on the adipokine profile, IGF1, and ghrelin levels in cord blood: relationship with glucose metabolism. Eur J Endocrinol 2009; 161: 381-389.

23. Mantzoros C, Petridou E, Alexe DM, Skalkidou A, Dessypris $\mathrm{N}$, Papathoma E, et al. Serum adiponectin concentrations in relation to maternal and perinatal characteristics in newborns. Eur J Endocrinol 2004; 151: 741-746.

24. Inoue M, Itabashi K, Nakano $\mathrm{Y}$, Nakano $\mathrm{Y}$, Tobe T. Highmolecular-weight adiponectin and leptin levels in cord blood are associated with anthropometric measurements at birth. Horm Res 2008; 70: 268-272.

25. Tsai PJ, Yu CH, Hsu SP, Lee YH, Chiou CH, Hsu YW, et al. Cord plasma concentrations of adiponectin and leptin in healthy term neonates: positive correlation with birthweight and neonatal adiposity. Clin Endocrinol 2004; 61: 88-93.

26. Dunger D, Ong K. Abundance of adiponectin in the newborn. Clin Endocrinol 2004; 61: 416-417.

27. Lindsay RS, Walker JD, Havel PJ, Hamilton BA, Calder AA, Johnstone FD. Adiponectin is present in cord blood but is unrelated to birth weight. Diabetes Care 2003; 26: 22442249.

28. Tung WK, Lin SJ, Hwang YS, Wu CM, Wang YH, Tsai WH. Association of cord plasma leptin with birth size in term newborns. Pediatr Neonatol 2009; 50: 255-260.

29. Mellati AA, Mazloomzadeh S, Anjomshoaa A, Alipour M, Karimi F, Mazloomi S, et al. Multiple correlations between cord blood leptin concentration and indices of neonatal growth. Arch Med Res 2010; 41: 26-32.

30. Ho SP, Wang LJ, Cheng I, Chen YL, Sung TC, Jow GM, et 
al. Association of plasma leptin levels with maternal body weight and body mass index in premature and term newborns. Pediatr Neonatol 2010; 51: 19-25.

31. Beltrand J, Nicolescu R, Kaguelidou F, Verkauskiene R, Sibony $\mathrm{O}$, Chevenne $\mathrm{D}$, et al. Catch-up growth following fetal growth restriction promotes rapid restoration of fat mass but without metabolic consequences at one year of age. PLOS One 2009; 4: e5343.

32. Bozzola E, Meazza C, Arvigo M, Travaglino P, Pagani S, Stronati M, et al. Role of adiponectin and leptin on body development in infants during the first year of life. Ital J Pediatr 2010; 36: 26.

33. Miras M, Ochetti M, Martin S, Silvano L, Sobrero G, Castro $\mathrm{L}$, et al. Serum levels of adiponectin and leptin in children born small for gestational age: relation to insulin sensitivity parameters. J Pediatr Endocrinol Metab 2010; 23: 463471.

34. Muhlhausler B, Smith SR. Early-life origins of metabolic dysfunction: role of the adipocyte. Trends Endocrinol Metab 2009; 20: 51-57.

35. Plagemann A, Harder T. Hormonal programming in perinatal life: leptin and beyond. Br J Nutr 2009; 101: 151-152.

36. Catalano PM, Farrell K, Thomas A, Huston-Presley L, Mencin P, de Mouzon SH, et al. Perinatal risk factors for childhood obesity and metabolic dysregulation. Am J Clin Nutr 2009; 90: 1303-1313.

37. Murphy MJ, Hosking J, Metcalf BS, Voss LD, Jeffery AN, Sattar N, et al. Distribution of adiponectin, leptin, and metabolic correlates of insulin resistance: a longitudinal study in British children; 1: Prepuberty (EarlyBird 15). Clin Chem 2008; 54: 1298-1306.

38. Darendeliler F, Poyrazoglu S, Sancakli O, Bas F, Gokcay G, Aki $S$, et al. Adiponectin is an indicator of insulin resistance in non-obese prepubertal children born large for gestational age (LGA) and is affected by birth weight. Clin Endocrinol 2009; 70: 710-716.

39. Bouhours-Nouet N, Dufresne S, de Casson FB, Mathieu E, Douay $\mathrm{O}$, Gatelais F, et al. High birth weight and early postnatal weight gain protect obese children and adolescents from truncal adiposity and insulin resistance: metabolically healthy but obese subjects? Diabetes Care 2008; 31: 10311036.

40. Budak E, Fernandez SM, Bellver J, Cervero A, Simon C, Pellicer A. Interactions of the hormones leptin, ghrelin, adiponectin, resistin, and PYY3-36 with the reproductive system. Fertil Steril 2006; 85: 1563-1581.

41. Fenichel RM, Dominguez JE, Mayer L, Walsh BT, Boozer C, Warren MP. Leptin levels and luteinizing hormone pulsatility in normal cycling women and their relationship to daily changes in metabolic rate. Fertil Steril 2008; 90: 11611168.

42. Spritzer PM, Poy M, Wiltgen D, Mylius LS, Capp E. Leptin concentrations in hirsute women with polycystic ovary syndrome or idiopathic hirsutism: influence on LH and relationship with hormonal, metabolic, and anthropometric measurements. Hum Reprod 2001; 16: 1340-1346.

43. You T, Yang R, Lyles MF, Gong D, Nicklas BJ. Abdominal adipose tissue cytokine gene expression: relationship to obesity and metabolic risk factors. Am J Physiol Endocrinol Metab 2005; 288: E741-E747.

44. Diez JJ, Iglesias P. The role of the novel adipocyte-derived hormone adiponectin in human disease. Eur $J$ Endocrinol 2003; 148: 293-300.

45. Cento RM, Proto C, Spada RS, Napolitano V, Ciampelli M, Cucinelli $F$, et al. Leptin levels in menopause: effect of estrogen replacement therapy. Horm Res 1999; 52: 269-273.

46. Asimakopoulos B, Milousis A, Gioka T, Kabouromiti G, Gianisslis G, Troussa A, et al. Serum pattern of circulating adipokines throughout the physiological menstrual cycle. Endocr J 2009; 56: 425-433.

47. Hardie L, Trayhurn P, Abramovich D, Fowler P. Circulating leptin in women: a longitudinal study in the menstrual cycle and during pregnancy. Clin Endocrinol 1997; 47: 101-106.

48. Lecke SB, Toscani M, Mario FM, Wiltgen D, Morsch DM, Spritzer PM. Influence of habitual physical activity on body composition, adipokine serum levels and gene expression on adipose tissue of PCOS women: a pilot study. Abstract book of the Androgen Excess and PCOS Society: Update Meeting. The heterogeneous nature of PCOS: Implications for treatment.Gramado: 2010.

49. Van Vugt DA. Brain imaging studies of appetite in the context of obesity and the menstrual cycle. Hum Reprod Update 2010; 16: 276-292.

50. Chung SC, Bond EF, Jarrett ME. Food intake changes across the menstrual cycle in Taiwanese women. Biol Res Nurs 2010; 12: 37-46.

51. Kleiblova P, Springer D, Haluzik M. The influence of hormonal changes during menstrual cycle on serum adiponectin concentrations in healthy women. Physiol Res 2006; 55: 661-666.

52. Rouen PA, Lukacs JL, Reame NE. Adipokine concentrations in nonobese women: a study of reproductive aging, body mass index, and menstrual cycle effects. Biol Res Nurs 2010; 12: 54-61.

53. Galvan RE, Basurto L, Saucedo R, Campos S, Hernandez $M$, Zarate A. [Adiponectin concentrations during menstrual cycle]. Ginecol Obstet Mex 2007; 75: 435-438.

54. Xita N, Papassotiriou I, Georgiou I, Vounatsou M, Margeli A, Tsatsoulis A. The adiponectin-to-leptin ratio in women with polycystic ovary syndrome: relation to insulin resistance and proinflammatory markers. Metabolism 2007; 56: 766-771.

55. Chu MC, Cosper P, Orio F, Carmina E, Lobo RA. Insulin resistance in postmenopausal women with metabolic syndrome and the measurements of adiponectin, leptin, resistin, and ghrelin. Am J Obstet Gynecol 2006; 194: 100-104.

56. Donato GB, Fuchs SC, Oppermann K, Bastos C, Spritzer PM. Association between menopause status and central adiposity measured at different cutoffs of waist circumference and waist-to-hip ratio. Menopause 2006; 13: 280-285.

57. Hong SC, Yoo SW, Cho GJ, Kim T, Hur JY, Park YK, et al. Correlation between estrogens and serum adipocytokines in premenopausal and postmenopausal women. Menopause 2007; 14: 835-840.

58. Antuna-Puente B, Feve B, Fellahi S, Bastard JP. Adipokines: the missing link between insulin resistance and obesity. Diabetes Metab 2008; 34: 2-11.

59. Lee JM, Kim SR, Yoo SJ, Hong OK, Son HS, Chang SA. The relationship between adipokines, metabolic parameters and insulin resistance in patients with metabolic syndrome and type 2 diabetes. J Int Med Res 2009; 37: 1803-1812.

60. Valencia MH, Zarate A, Galvan RE. [Adiponectin levels in perimenopause]. Ginecol Obstet Mex 2008; 76: 450-453. 